\title{
Oral Supplementation of Specific Collagen Peptides Has Beneficial Effects on Human Skin Physiology: A Double-Blind, Placebo-Controlled Study
}

\author{
E. Prokscha \\ D. Segger ${ }^{c}$ \\ J. Degwert ${ }^{c}$ \\ M. Schunck ${ }^{b}$ \\ V. Zague ${ }^{d}$ \\ S. Oesser ${ }^{b}$
}

${ }^{a}$ Department of Dermatology, University of Kiel, and ${ }^{\mathrm{b}} \mathrm{CRI}$, Collagen Research Institute, Kiel, and ${ }^{\mathrm{C} S k i n}$ Investigation and

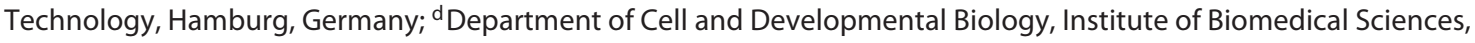
University of São Paulo, São Paulo, Brazil

\section{Key Words}

Collagen peptides · Collagen hydrolysate · Skin · Elasticity ·

Hydration · Roughness

\begin{abstract}
Various dietary supplements are claimed to have cutaneous anti-aging properties; however, there are a limited number of research studies supporting these claims. The objective of this research was to study the effectiveness of collagen hydrolysate $(\mathrm{CH})$ composed of specific collagen peptides on skin biophysical parameters related to cutaneous aging. In this double-blind, placebo-controlled trial, 69 women aged $35-55$ years were randomized to receive $2.5 \mathrm{~g}$ or $5.0 \mathrm{~g}$ of $\mathrm{CH}$ or placebo once daily for 8 weeks, with 23 subjects being allocated to each treatment group. Skin elasticity, skin moisture, transepidermal water loss and skin roughness were objectively measured before the first oral product application (t0) and after 4 (t1) and 8 weeks (t2) of regular intake. Skin elasticity (primary interest) was also assessed at follow-up 4 weeks after the last intake of $\mathrm{CH}$ ( $\mathrm{t} 3$, 4-week regression phase). At the end of the study, skin elasticity in both $\mathrm{CH}$ dosage groups showed a statistically significant improvement in comparison to placebo. After 4 weeks of follow-up treat-
\end{abstract}

\section{KARGER}

E-Mail karger@karger.com

www.karger.com/spp ment, a statistically significantly higher skin elasticity level was determined in elderly women. With regard to skin moisture and skin evaporation, a positive influence of $\mathrm{CH}$ treatment could be observed in a subgroup analysis, but data failed to reach a level of statistical significance. No side effects were noted throughout the study.

C) 2013 S. Karger AG, Basel

\section{Introduction}

The epidermis, the fibrous collagen and elastin network of the dermis, and the subcutaneous fat tissue give rise to the biomechanical and physiological properties of the skin [1]. Several factors influence the appearance, structure and integrity of the skin, including aging, hormones, UV radiation and nutrition. During aging, qualitative and quantitative changes occur in the skin. Loss of elasticity, reduction in the epidermal thickness and collagen content and increased wrinkling are the features of aging skin [2].

An important trend in skin care is the use of diet and oral supplements to improve the skin's appearance and structure. Healthy skin largely reflects the general health 
status and as such the skin is influenced by the consumption of dietary substances, including vitamins and antioxidants, fatty acids and hydrolyzed proteins [3]. Therefore, the effects of nutritional factors on the skin have received increasing attention, and a number of clinical studies indicated that dietary supplementation can modulate skin functions [4].

Collagen hydrolysate $(\mathrm{CH})$ has long been used in pharmaceuticals and food supplements for improving skin and cartilage tissues. It is absorbed in the digestive tract, appears in the human blood partly in a small peptide form $[5,6]$ and is accumulated in skin for up to $96 \mathrm{~h}$ as shown by Oesser et al. [7]. On the basis of in vitro studies, collagen peptides (CPs) have shown the ability of exerting potent antioxidative activities in different oxidative systems [8-11].

Moreover, $\mathrm{CH}$ has been reported to have beneficial biological functions in skin. Studies have shown that foodderived CPs in human blood are chemotactic for skin fibroblasts [12] and increase the migration and growth of mouse skin fibroblasts [13]. Matsuda et al. [14] investigated effects of $\mathrm{CH}$ ingestion on fibroblast and collagen densities of pig skin and showed that density and diameter of fibroblasts and density of collagen fibrils were significantly larger in the $\mathrm{CH}$ group than in the control groups. Tanaka et al. [15] demonstrated that $\mathrm{CH}$ ingestion inhibited UVB-induced decrease of type I collagen, thus improving skin conditions in mice.

Recently, Zague et al. [16] investigated the effect of daily ingestion of $\mathrm{CH}$ on skin extracellular matrix proteins in rats. The relative amount of type I and IV collagens was significantly increased after $\mathrm{CH}$ intake compared with the reference diet group (casein). Moreover, $\mathrm{CH}$ uptake significantly decreased both pro-enzyme and active forms of matrix metalloproteinase- 2 compared with casein and control groups. This implied that the effect of $\mathrm{CH}$ was protein-specific and did not depend merely on an increase of amino acid intake. The authors suggested that $\mathrm{CH}$ may reduce aging-related changes of the extracellular matrix by stimulating anabolic processes in skin tissue.

Although there is convincing evidence, from the preclinical perspective, that $\mathrm{CH}$ ingestion may improve skin conditions and even protect skin from UV damage, little is known about the clinical effects of $\mathrm{CH}$ on skin parameters and health. The aim of our study was to evaluate the potential benefits of an oral supplement containing specific $\mathrm{CP}$ on skin parameters related to cutaneous physiology and aging, including skin elasticity, hydration, roughness and transepidermal water loss (TEWL).
Table 1. Demographic data of the volunteers per treatment group

\begin{tabular}{lcc}
\hline Subjects, $\mathrm{n}$ & $2.5 \mathrm{~g} \mathrm{CH}$ & 23 \\
& $5 \mathrm{~g} \mathrm{CH}$ & 23 \\
& $2.5 \mathrm{~g}$ placebo & 23 \\
\hline Age (mean) & $2.5 \mathrm{~g} \mathrm{CH}$ & 48.7 \\
& $5 \mathrm{~g} \mathrm{CH}$ & 47.2 \\
& $2.5 \mathrm{~g} \mathrm{placebo}$ & 47.9 \\
\hline Age (SD) & $2.5 \mathrm{~g} \mathrm{CH}$ & 4.8 \\
& $5 \mathrm{~g} \mathrm{CH}$ & 5.7 \\
& $2.5 \mathrm{~g} \mathrm{placebo}$ & 5.2 \\
\hline Age (min.) & $2.5 \mathrm{~g} \mathrm{CH}$ & 35.3 \\
& $5 \mathrm{~g} \mathrm{CH}$ & 36.1 \\
& $2.5 \mathrm{~g} \mathrm{placebo}$ & 36.2 \\
\hline Age (max.) & $2.5 \mathrm{~g} \mathrm{CH}$ & 55.4 \\
& $5 \mathrm{~g} \mathrm{CH}$ & 54.9 \\
& $2.5 \mathrm{~g} \mathrm{placebo}$ & 54.3 \\
\hline
\end{tabular}

Age is expressed in years.

\section{Materials and Methods}

\section{Test Product}

The test product used in this study was a $\mathrm{CH}$ composed of different specific CPs derived from a special hydrolysis of porcine type I collagen. The product was provided by GELITA AG (Eberbach, Germany), commercially available under the name VERISOL ${ }^{\circledR}$. The product is clearly defined by MALDI-MS mass peak fingerprint with specific CPs of an average molecular weight of $2.0 \mathrm{kDa}$.

\section{Study Design}

The study was carried out as a monocentric, double-blinded, randomized, placebo-controlled supplementation study on the effects of a specific $\mathrm{CH}$ on skin elasticity (primary interest) and skin hydration, as well as on TEWL and skin roughness (secondary interests) after 8 weeks of daily intake.

The study was approved by the Freiburger Ethik-Kommission International, Freiburg, Germany, and adhered to current Good Clinical Practice regulations. All test subjects received detailed information listing every relevant single parameter to the study. All subjects gave signed informed consent after written information and a possibility for further questioning.

Subjects

A total of 69 healthy female subjects were enrolled in the study; 23 subjects were randomized to each of 3 treatment groups to receive a daily dose of either 2.5 or $5.0 \mathrm{~g}$ of $\mathrm{CH}$ or $2.5 \mathrm{~g}$ of the placebo (maltodextrin). There were no differences between the treatment and the placebo groups (table 1$)$ with regard to age $(p=0.664)$.

The products were taken orally by the subjects at home according to the instructions given by the investigator. The powder was to be dissolved in water or any other cold liquid.

Prior to the beginning of oral treatment and data acquisition a preconditioning period of at least 7 days was conducted. Within
Proksch/Segger/Degwert/Schunck/

Zague/Oesser 
this period the volunteers had to refrain from using any leave-on products on the test areas. The study participants were not allowed to change their usual skin care routine. Moreover, treatment with dermatological therapeutics on the test areas was not allowed within 6 weeks prior to the start of the study. In addition to that, changes in living or dietary habits, consumption of any additional nutritional supplement or vitamin preparations, treatment of the volar forearms with cosmetic and dermatological skin care products and intensive exposure to sun or UV light were prohibited during the study.

\section{Inclusion Criteria}

The inclusion criteria were as follows: healthy females ranging in age from 35 to 55 years (homogeneous distribution between treatment groups); dry skin on forearms according to self-assessment; phototype I-IV (Fitzpatrick scale); general good health and mental condition; personal informed consent to participate in the study; personal presence on the predefined days at the institute, and willingness and capability to follow the study rules and a fixed schedule.

\section{Exclusion Criteria}

The exclusion criteria was as follows: any deviation from the above-mentioned inclusion criteria; acute skin diseases (e.g. atopic eczema, neurodermatitis or psoriasis) on the test areas or other dermatological disorders (e.g. scars, sunburn or moles); food allergies against ingredients of the test products; gastrointestinal diseases or indigestions; tattoos on the test areas; topical medication on the test area within 6 weeks prior to study start; systemic medication with anti-inflammatory agents or antibiotics within 2 weeks prior to study start; systemic medication with corticoids and/or antihistamines within 4 weeks prior to study start; other systemic medication within 4 weeks prior to study start; systemic illness of the subject at the beginning of the study; pregnancy or period of breast feeding; immunological disorders; severe disorders within 6 months prior to study start (e.g. cancer, acute cardiac and circularity disorders, severe diabetes, or alcohol or drug abuse); participation in other studies with cosmetic products on the test areas within 2 weeks prior to study start or during the study; participating in a study with a pharmaceutical preparation within 4 weeks prior to study start; intake of nutritional supplements within 4 weeks prior to study start and, except for the test products, during the study; change in lifestyle or eating habits during the study; treatment with leave-on products or oily or moisturizing skin-cleansing products on arms; change in usual skin care routine; intensive sun or artificial UV exposure (solarium) on the test areas within 1 week prior to study start or during the study; swimming, sauna or intensive sport within 1 day prior to measurements; lack of compliance, and intellectual or mental inability to follow the study instructions.

\section{Assessments}

\section{Test Areas}

The test areas were the inner aspects of both forearms ( 1 test area per volar forearm). The test areas on the forearms reached an area of $5 \times 5 \mathrm{~cm}$. Skin hydration, skin elasticity and TEWL were measured on the left forearm while skin roughness was assessed on the right forearm. On every measurement day, the subjects had to expose their uncovered test areas to the indoor climate conditions $\left(21.5 \pm 1^{\circ} \mathrm{C}\right.$ and $50 \pm 5 \%$ relative humidity) for at least $30 \mathrm{~min}$.

Beneficial Effects of Specific Collagen

Peptides on Human Skin Physiology

\section{Measurement Times}

There were 4 measurement times: immediately before starting the product treatment $(\mathrm{t} 0)$, after $4(\mathrm{t} 1)$ and 8 weeks $(\mathrm{t} 2)$ of daily product intake, and 4 weeks after the last intake (t3, 4-week regression phase, only for the skin elasticity parameter).

The subject's compliance (dosage and way of intake) and tolerance towards the products were checked after 1, 4 and 6 weeks of intake.

Measurement of Skin Elasticity

Skin elasticity was performed with the Cutometer ${ }^{\circledR}$ MPA 580 (Courage \& Khazaka, Cologne, Germany) as described by Segger et al. [17] and Segger and Schonlau [18]. Briefly, the extension of the skin was tested in response to a suction vacuum induced above the skin test area with a 350-mbar vacuum (5-second exposure and non-exposure period) and 1 cycle per measurement was detected. To analyse skin elasticity, the $\mathrm{R} 5$ value ( $\mathrm{Ur} / \mathrm{Ue}$, immediate recovery/elastic deformation) was recorded. This parameter has proven to be most suitable in detecting age-related skin alterations [19, 20]. The measurement of each test area was repeated 3 times.

\section{Measurement of Skin Hydration}

Assessment of skin surface hydration by electrical capacitance was carried out using the Corneometer ${ }^{\circledR}$ CM 825 (Courage \& Khazaka), which measures the reactive capacitance of the skin, using the stratum corneum as a dielectric membrane. Measurements are arbitrarily expressed as indices of hydration, which increase with increasing skin hydration; 10 individual measurements per application site and control were performed.

\section{Measurement of TEWL}

Using the DermaLab ${ }^{\circledR}$ (Cortex Instruments, Regensburg, Germany) device, the TEWL expressed in $\mathrm{g} / \mathrm{m}^{2} / \mathrm{h}$ was evaluated on each site by continuous data logging over a 45 -second period. From the continuous TEWL plots, the mean value and the corresponding standard deviations of the last 8 determined TEWL data during this measurement sequence were computed. The measurement of each test area was repeated 3 times.

\section{Measurement of Skin Roughness}

The skin roughness was assessed by silicone imprints using the PRIMOS Compact (GFMesstechnik, Teltow, Germany) device for analysis with a measuring field size of $40 \times 30 \mathrm{~mm}$ and a lateral to spatial resolution of 62 to $6 \mu \mathrm{m}$. Immediately after mixing the hardening agent with the silicone rubber, the material was applied onto the defined test areas and left for 5 min to harden. Then, the imprints were carefully removed from the skin and allowed to harden completely for $24 \mathrm{~h}$. Each replica was analysed with the optical measuring instrument, PRIMOS Compact. The measurement parameters were 'replica fine' and 'slow measurement'. Three separate sites of each replica were analysed. The relief picture was computed according to the standard procedure using the polynom level 5 . Skin roughness was evaluated by analysing the roughness parameter area (SQ value). The total area for the SQ evaluation was about $18.4 \times 13.8 \mathrm{~mm}$, with the single areas for the SQ evaluations being about $3.7 \times 2.8 \mathrm{~mm}$.

\section{Statistical Analysis}

The study objectives were analysed by Skin Investigation and Technology Hamburg GmbH, Hamburg, Germany, using the 
computer software Microsoft Excel and STATISTICA. Microsoft Excel was used for the calculation of the relative data, minimum and maximum values, means and standard deviations. STATISTICA was used to analyse the data distribution (KolmogorovSmirnov test) and to analyse the significance of differences (oneway ANOVA with the post hoc Fisher LSD test or Kruskal-Wallis ANOVA with post hoc multiple comparison of mean ranks for all groups). The hypothesis of a normal distribution was accepted when there was a $\mathrm{p}$ value $>0.025$ (primary interests). Concerning the differences between the treatment situations, a $p$ value of 0.05 was considered as a statistically significant difference.

To test for significance of differences between the treatment groups, either the one-way ANOVA (the post hoc Fisher LSD) for normally distributed data or the Kruskal-Wallis ANOVA (post hoc multiple comparison of mean ranks for all groups) for not normally distributed data was to be used. The following treatment situations were compared: treatment situations at points in time t0 (original data), $\mathrm{t} 1, \mathrm{t} 2$ and $\mathrm{t} 3$ (data relative to $\mathrm{t} 0$ ). The data relative to t0 were computed as follows: treatment situation at $\mathrm{tx}=1,2,3$ / treatment situation at $\mathrm{t} 0$.

In addition, a subgroup analysis was done between the 3 treatment groups. All volunteers within the groups were subdivided as being younger or older than 50 years (table 2 ). To test for significance of differences between treatment groups the one-way ANOVA (the post hoc Fisher LSD) for normally distributed data was used. The following treatment situations were compared: $\mathrm{t} 2$ and $\mathrm{t} 3$ (data relative to $\mathrm{t} 0$ ). The data relative to $\mathrm{t} 0$ were computed as follows: treatment situation at $\mathrm{tx}=2,3$ /treatment situation at $\mathrm{t} 0$.

\section{Results}

There were 7 dropouts, none of which were related to the product intake or the study procedure in general. The t0 data of only 1 subject from the placebo group was excluded from data analysis because there were no postbaseline data available. There were no discomfort or adverse reactions reported.

\section{Skin Elasticity}

There was no significant difference in skin elasticity levels between the treatment and placebo groups prior to the product treatment $(\mathrm{p}=0.46)$. The starting level (R5 value $=\mathrm{Ur} / \mathrm{Ue})$ was about $0.85-0.89( \pm 0.11-0.13)$. Concerning the data relative to placebo, both dosages of $\mathrm{CH}$ showed statistically significant improved skin elasticity levels after 4 and 8 weeks of intake (mean 7\%; p $<0.05$ in all cases), as shown in figure 1 . There were no statistically significant differences between the two dosages of $\mathrm{CH}$. In a more detailed subgroup analysis it could be demonstrated that the positive impact of $\mathrm{CH}$ treatment on skin elasticity seemed to be more pronounced in elderly women aged over 50 years (fig. 2).

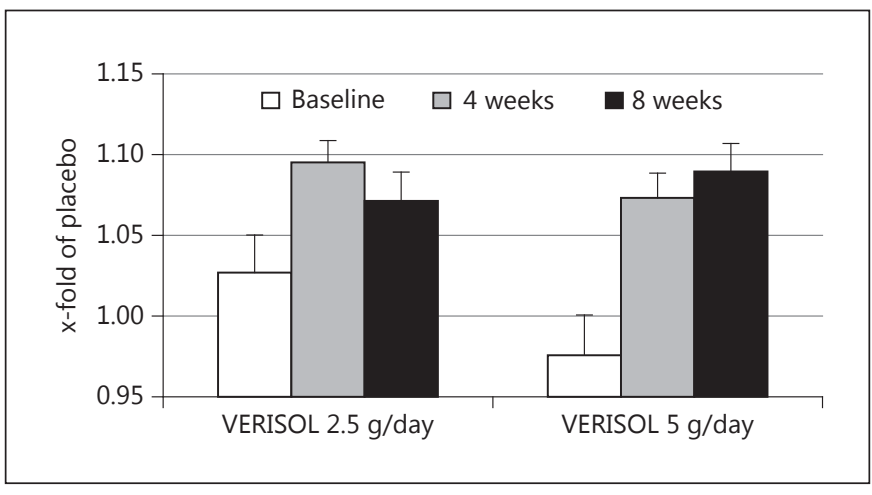

Fig. 1. Skin elasticity changes during the time of treatment. Prior to the beginning of the treatment, no statistically significant difference in skin elasticity was detected in comparison to the placebo group. Both $\mathrm{CH}$-treated groups showed a statistically higher elasticity after 4 and 8 weeks of $\mathrm{CH}$ ingestion (mean \pm SEM, $\mathrm{n} \geq 22, \mathrm{p}<0.05$ ).

Table 2. Age-related subcategories per treatment group

\begin{tabular}{lll}
\hline Treatment group & $<50$ years, $\mathrm{n}$ & $\geq 50$ years, $\mathrm{n}$ \\
\hline $2.5 \mathrm{~g} \mathrm{CH}$ & 14 & 9 \\
$5 \mathrm{~g} \mathrm{CH}$ & 15 & 8 \\
2.5 g placebo & 13 & 9 \\
\hline
\end{tabular}

At 4 weeks after the last product intake (4-week regression phase), the treatment subgroup of elderly women still showed statistically significantly higher skin elasticity levels than the placebo group ( $\mathrm{p}<0.05$, fig. 3 ), with about $98 \%$ of the positive effect for skin elasticity after having stopped $\mathrm{CH}$ intake (data not shown).

\section{Skin Hydration}

The starting level of skin hydration was about 27.9$30.0 \mathrm{AU}( \pm 4.3-6.1)$ with no statistical difference between treatment groups and placebo control at the baseline $(\mathrm{p}=$ 0.31 ). Considering the data relative to placebo of the entire studied group overall, there was no statistically significant difference in skin hydration levels between the treatment and placebo groups after $4(\mathrm{p}=0.90)$ and 8 weeks ( $\mathrm{p}=0.96$ ) of daily intake (fig. 4$)$. However, subgroup analysis revealed an increased skin hydration by $11-14 \%$ in women over 50 years old, but data failed statistical significance (fig. 5).

\section{Transepidermal Water Loss}

At the beginning of the observation period no statistically significant difference in the TEWL levels between 
Fig. 2. Skin elasticity changes in age-related subgroups. Skin elasticity was statistically significantly increased in elderly women $(50+)$ after both $\mathrm{CH}$ dosages in comparison to the placebo control treatment $(n \geq 9)$.

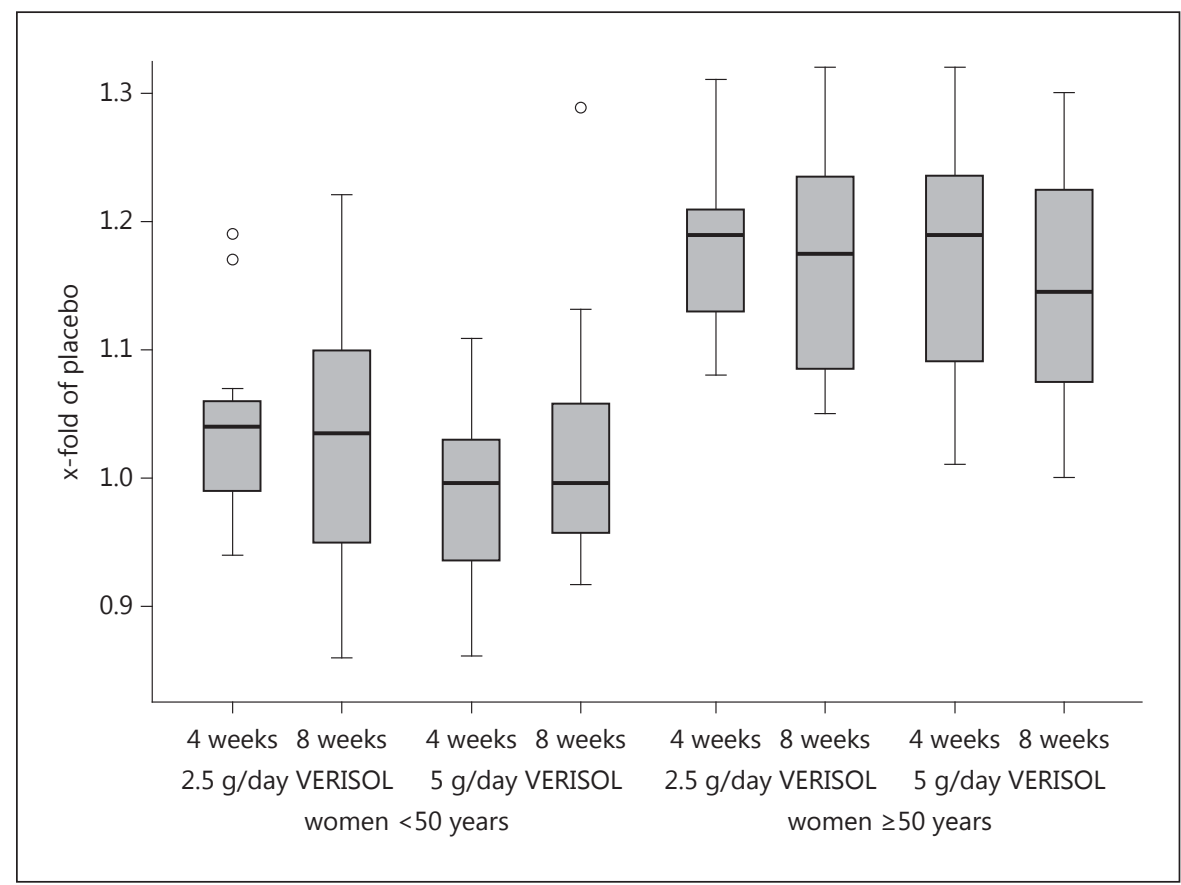

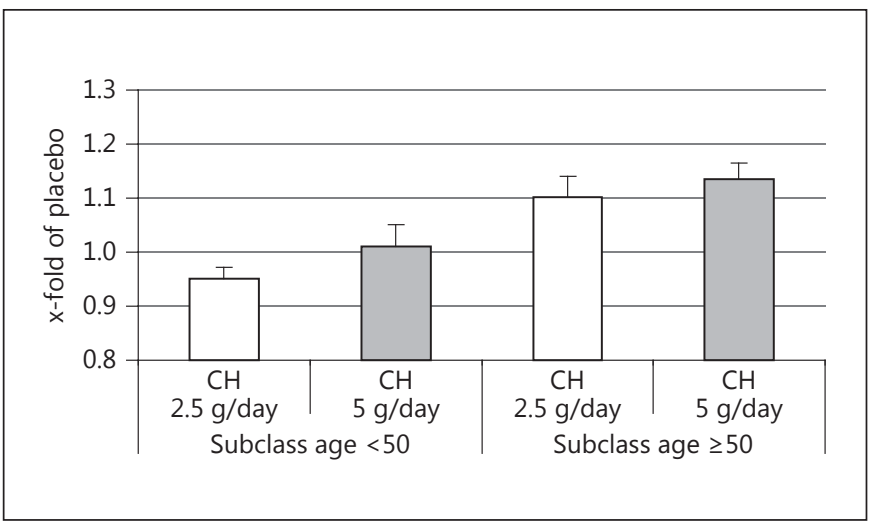

Fig. 3. Long-lasting effect on skin elasticity changes in age-related subcategories. At 4 weeks after the last $\mathrm{CH}$ intake, skin elasticity in elderly women $(50+)$ was statistically significantly increased in both $\mathrm{CH}$ dosages in comparison to the placebo control treatment (mean \pm SEM, $\mathrm{n} \geq 9, \mathrm{p}<0.05$ ).

treatment and placebo groups could be observed ( $\mathrm{p}=$ $0.99)$. The starting level was about $8.0 \mathrm{~g} / \mathrm{m}^{2} / \mathrm{h}( \pm 1.2-1.3)$. Concerning the data relative to placebo, there was no statistically significant difference in skin evaporation between treatment and placebo groups after $4(\mathrm{p}=0.88)$ and 8 weeks ( $\mathrm{p}=0.90)$ of daily intake (fig. 6). In women over 50 years of age skin evaporation was reduced by $6-7 \%$. There was no statistically significant difference in the moisturizing effect in this subgroup (fig. 7).

Beneficial Effects of Specific Collagen

Peptides on Human Skin Physiology

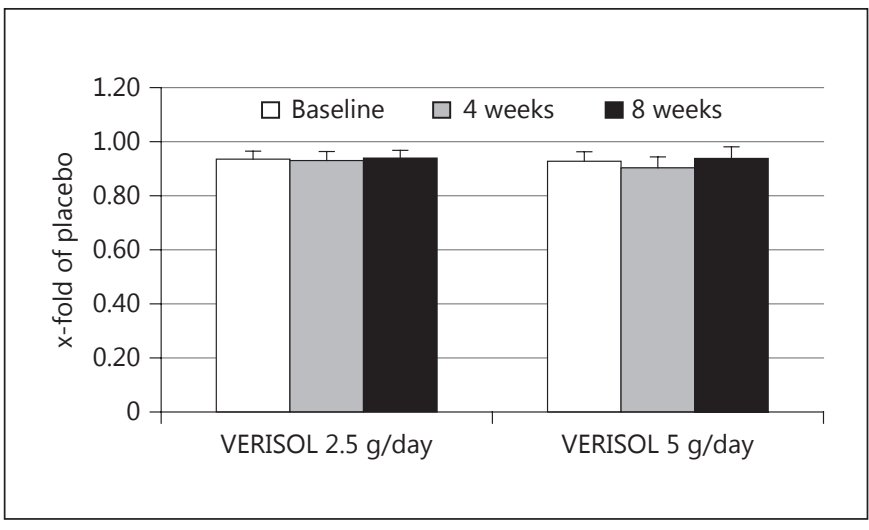

Fig. 4. Skin hydration changes during the time of treatment. Within the entirety of both $\mathrm{CH}$-treated groups, no skin hydration effects were observed during the time of treatment (mean \pm SEM, $n \geq 22$ ).

\section{Skin Roughness}

There was no statistically significant difference in skin roughness between treatment and placebo groups at the baseline $(\mathrm{p}=0.59)$. The starting level was about 18.3-19.9 $\mu \mathrm{m}( \pm 4.2-6.9)$. As demonstrated in figure 8 , changes of skin smoothness relative to placebo failed to reach a level of statistical significance between the treatment and placebo groups after $4(\mathrm{p}=0.61)$ and 8 weeks $(\mathrm{p}=0.63)$ of daily intake. 
Fig. 5. Skin hydration changes in age-related subgroups. Skin hydration was increased in elderly women $(50+) 8$ weeks after both $\mathrm{CH}$ dosages in comparison to the placebo control treatment $(n \geq 9)$.

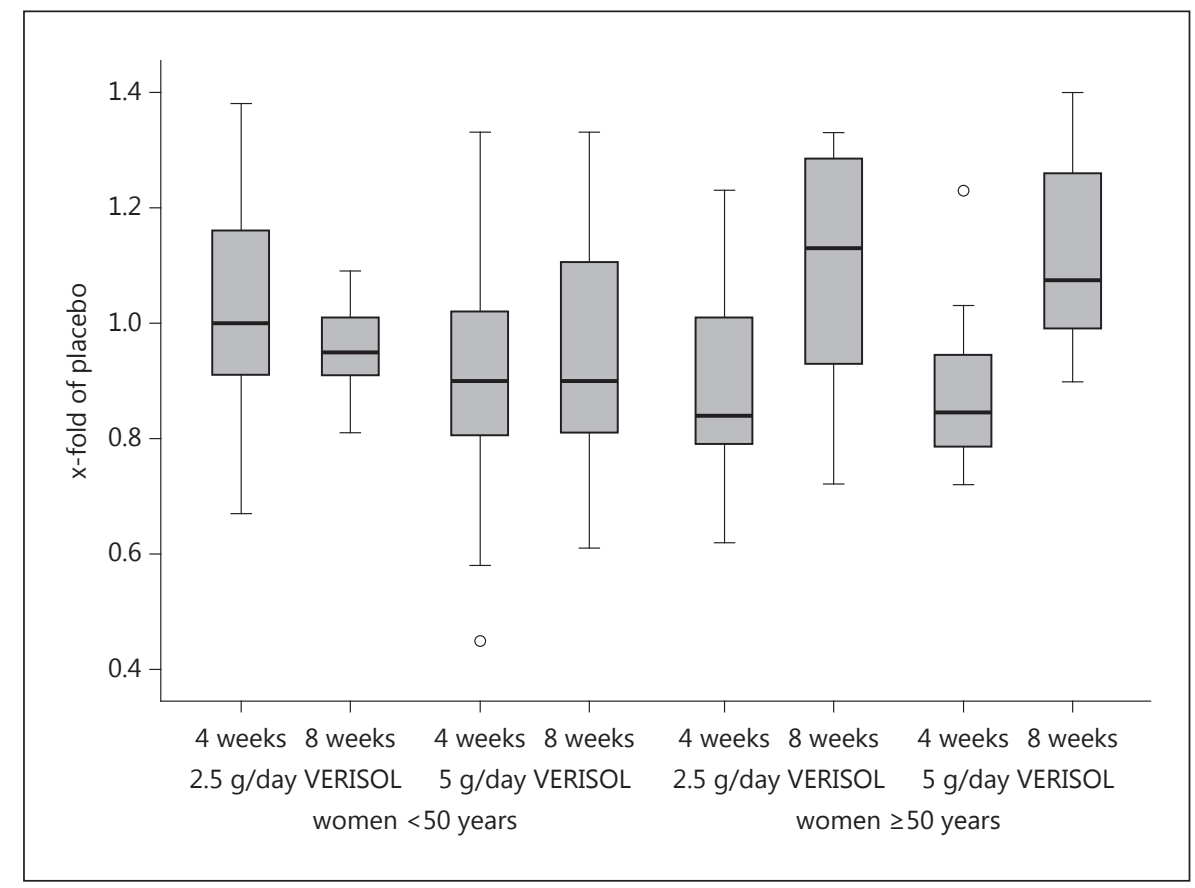

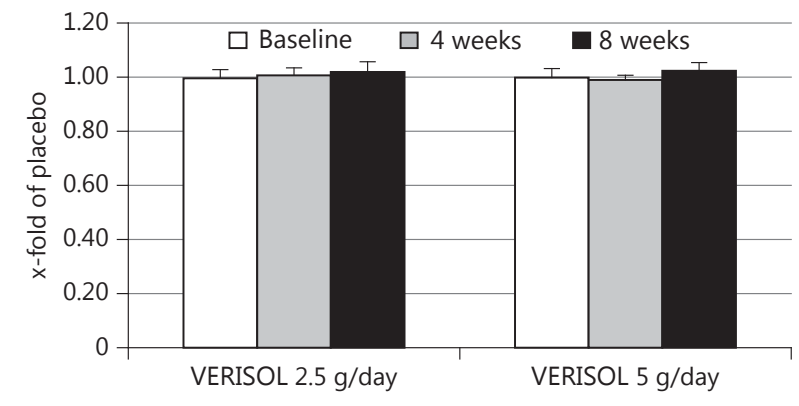

Fig. 6. Skin evaporation changes during the time of treatment. Within the entirety of both $\mathrm{CH}$-treated groups, no skin evaporation effects were observed during the time of treatment (mean \pm SEM, $\mathrm{n} \geq 22$ ).

\section{Discussion}

Human skin physiology changes during the course of life. While chronological or intrinsic aging is characterized by a reduction of skin thickness, loss of skin elasticity, collagen fibre degeneration, xerosis and wrinkle formation [21-27], extrinsic or photoaging caused by sunlight exposition leads to deep-wrinkled, dyspigmented skin and the formation of small dilated blood vessels near the skin surface (telangiectasia) [28]. It can be assumed that the most prominent physiological alterations in chronological and photoaging are localized in the dermis and caused by the metabolism of dermal collagen fibres.

During the last decade the influence of ingested $\mathrm{CH}$ on skin physiology has been investigated by several groups. In experimental studies the authors examined fibroblast growth, dermal extracellular matrix synthesis, antioxidative protection and reduction of skin wrinkle formation $[11,13,15,22,23,29-34]$. These investigations suggested that CPs may improve skin appearance and function in skin tissue.

So far, only a few controlled clinical studies have been performed to investigate the effect of orally administered $\mathrm{CH}$ on various skin parameters $[4,35]$.

To the best of our knowledge, the present study is the first clinical trial demonstrating the efficacy of a specific low dosage ( $2.5 \mathrm{~g} /$ day $)$ of $\mathrm{CH}$ on skin physiology. The results clearly revealed that both dosages ( 2.5 and $5.0 \mathrm{~g}$ ) of the specific $\mathrm{CH}$ had a beneficial effect on skin physiology, as indicated by increased skin elasticity after 4 weeks of daily consumption. The observed effect was statistically significant $(\mathrm{p}<0.05)$ after 4 and 8 weeks in the treatment groups compared to placebo. In some women a maximum increase of skin elasticity up to $30 \%$ could be observed after an 8 -week treatment. Interestingly, only a relatively small number of 23 women per group were needed to 
Fig. 7. Skin evaporation changes in age-related subgroups. TEWL was reduced in elderly women 4 and 8 weeks after $\mathrm{CH}$ treatment in comparison to placebo administration $(\mathrm{n} \geq 9)$.

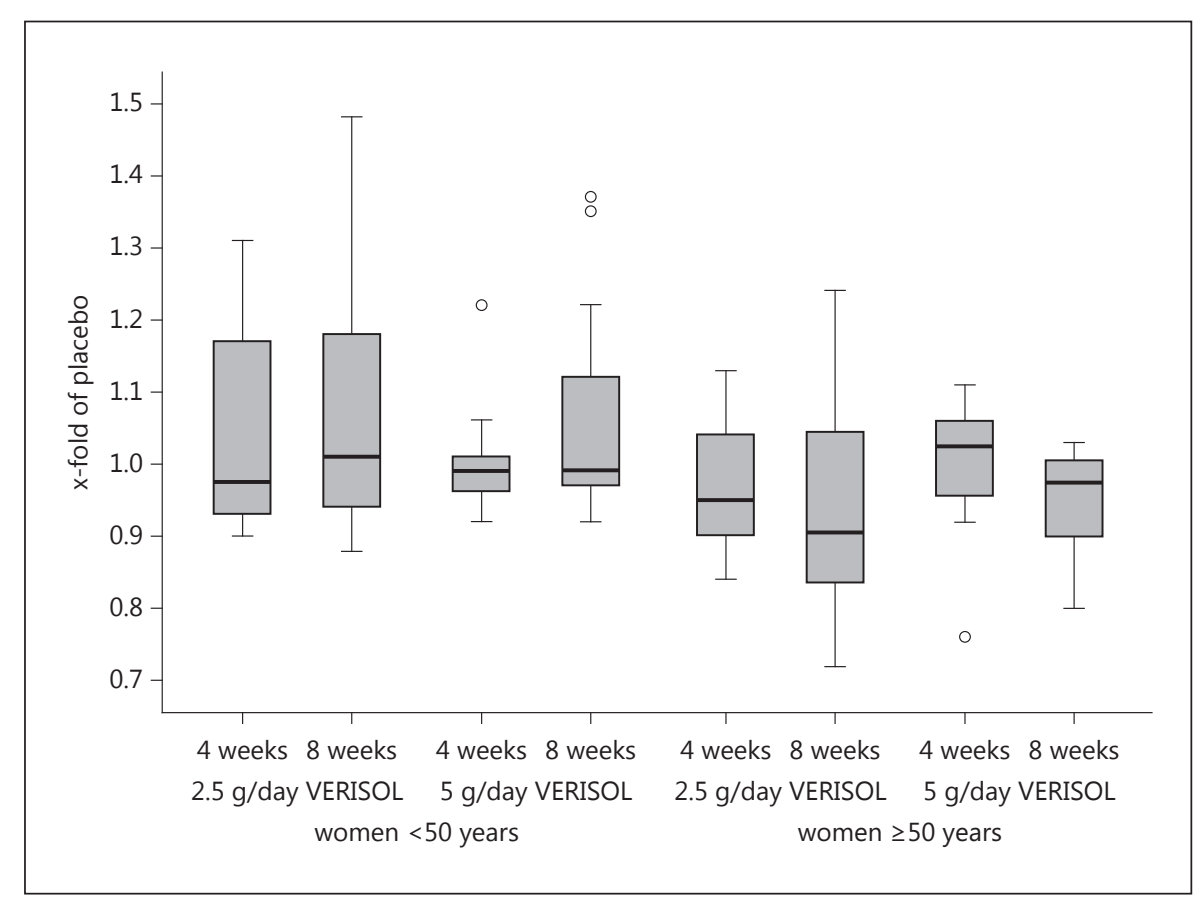

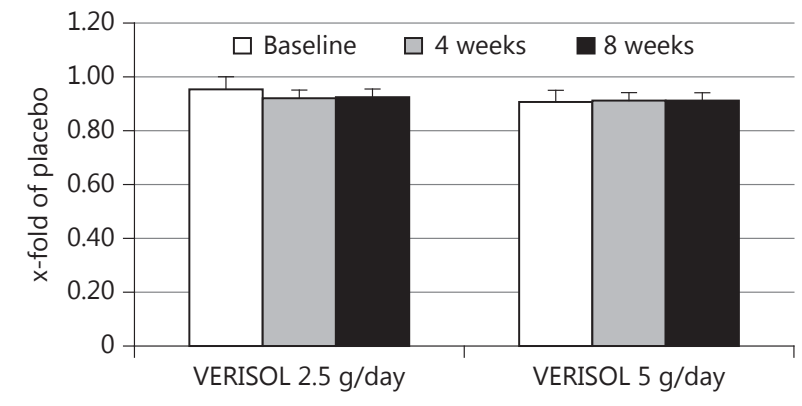

Fig. 8. Skin roughness changes during time of treatment. Within the entirety of both $\mathrm{CH}$-treated groups no skin roughness effects were observed during the time of treatment (mean \pm SEM, $\mathrm{n} \geq 22$ ).

clearly demonstrate the efficacy of the verum. The group size was predefined by a power calculation (test power $80 \%$ ) based on previously published investigations.

In a subgroup analysis it could be demonstrated that the statistically significant increase in skin elasticity after $\mathrm{CH}$ ingestion was even more pronounced in women aged over 50 years compared to younger women $(\mathrm{p}<0.05)$. The validity of these results could be confirmed by a power calculation. Due to the small variances within the measured data a test power of more than $90 \%$ was determined.
The fact that this positive effect was still detectable at the end of the 4-week washout phase suggests a long-lasting dermal physiological effect. These findings are in contrast to topical products which should be mostly effective in the skin ageing-encountered superficial dermis and epidermis [36], where improved skin elasticity is predominantly caused by an increase in epidermal hydration [37, 38]. Xhauflaire-Uhoda et al. [39] investigated anti-wrinkle effects of topically used skin care products. They found no evidence of skin moisturizing after stopping treatment and, moreover, the low increase in skin hydration corresponded to normal newly generated corneocytes from deeper skin layers. They found out that the tested cream and lotion did not penetrate deeply into the skin barrier, and an anti-wrinkle effect after topical treatment could have been the result of the generating of a skin surface film which hindered water evaporation. Moreover, beyond the effectivity of topical treatments, Buraczewska et al. [40] (2007) could show that a topical longterm treatment with hydrocarbon cream did not elevate skin hydration but led to an impaired skin barrier and an increased TEWL.

Skin elasticity is a very important marker for skin aging. In a clinical study on postmenopausal women, Sumino et al. [26] investigated the decline of skin elasticity per year in comparison to premenopausal subjects. From the finding that skin elasticity was negatively correlated with age 
and years after the climacteric period, they calculated a $0.55 \%$ declining skin elasticity per year after menopause. It is well known that besides skin hydration, elasticity is especially influenced by dermal collagen $[41,42]$. This relation was observed by Marini et al. [43], who described a correlation between skin elasticity and hydration and collagen type I RNA expression after oral treatment.

Experimental studies on primary human dermal fibroblasts demonstrated a stimulatory effect of the specific $\mathrm{CH}$ used in this study on the expression of skin extracellular matrix macromolecules. After supplementation of the CPs to fibroblast cultures a pronounced increase of type I collagen expression as well as in the expression of proteoglycans like biglycan, decorin and versican could be observed (data not shown). Although further investigations are needed, it could be speculated that the observed positive effect of $\mathrm{CH}$ on skin elasticity might be caused by an increase of dermal matrix macromolecule biosynthesis.

With regard to the investigated skin moisturizing parameters, overall results revealed that skin evaporation and skin hydration were unchanged in both $\mathrm{CH}$ treatment groups. However, a tendency of reduced skin evaporation and an increased skin moisturizing effect were observed in elderly women as indicated in the subgroup analysis. Besides loss of skin elasticity, xerosis is described as a common skin problem of the elderly [44-46]. Thus, data suggest that, especially in this group, $\mathrm{CH}$ treatment might have a positive impact on skin hydration.

Interestingly, although skin moisture content and TEWL should correlate with skin microtexture and skin roughness, no changes of this parameter could be measured in the present study.
Over the treatment period of 8 weeks no visible changes of the skin roughness by $\mathrm{CH}$ ingestion in comparison to placebo were detectable. It might be speculated that the duration of treatment and localization of measurement at the sunlight-protected inner side of the forearm might be responsible for these observations. On the other hand, Sato et al. [47] observed a significant correlation between skin roughness and the thickness of the stratum corneum. As it is known that skin thickness decreases with age, this aspect could possibly explain the lack of a pronounced effect of $\mathrm{CH}$ on skin roughness, as detected in the present study [1].

In conclusion, the results of the study clearly demonstrated that the oral intake of a specific $\mathrm{CH}$ led to a statistically significant increase in skin elasticity. Moreover, a skin moisturizing effect could be observed in elderly women, although results did not reach a level of statistical significance. In contrast to most topically applied substances this positive effect of orally applied $\mathrm{CH}$ on skin health seems to be long-lasting, especially in women over 50 years of age. Overall $\mathrm{CH}$ intake over a longer period seems to have a positive impact on skin health. It has to be stated that the demonstrated efficacy refers to the specific CP composition (VERISOL ${ }^{\circledR}$ ) used in this study and could not be extrapolated to $\mathrm{CH}$ in general.

More research is needed, especially regarding the mode of action and to confirm the clinical efficacy. In a follow-up clinical study it could be interesting to investigate the effect of a CP supplementation on dermal matrix macromolecule synthesis and the clinical efficacy, for example on wrinkle formation.

\section{References}

$>1$ Smalls LK, Randall WR, Visscher MO: Effect of dermal thickness, tissue composition, and body site on skin biomechanical properties. Skin Res Technol 2006;12:43-49.

-2 Calleja-Agius J, Muscat-Baron Y, Brincat MP: Skin ageing. Menopause Int 2007;13:60-64.

$>3$ Draelos ZD: Nutrition and enhancing youthful-appearing skin. Clin Dermatol 2010;28: 400-408.

-4 Zague V: A new view concerning the effects of collagen hydrolysate intake on skin properties. Arch Dermatol Res 2008;300:479-483.

5 Ohara H, Matsumoto H, Ito K, Iwai K, Sato $\mathrm{K}$ : Comparison of quantity and structures of hydroxyproline-containing peptides in human blood after oral ingestion of gelatin hydrolysates from different sources. J Agric Food Chem 2007;55:1532-1535.
6 Iwai K, Hasegawa T, Taguchi Y, Morimatsu F, Sato K, Nakamura Y, Higashi A, Kido Y, Nakabo Y, Ohtsuki K: Identification of food-derived collagen peptides in human blood after oral ingestion of gelatin hydrolysates. J Agric Food Chem 2005;53:6531-6536.

7 Oesser S, Adam M, Babel W, Seifert J: Oral administration of ${ }^{14} \mathrm{C}$-labeled gelatin hydrolysate leads to an accumulation of radioactivity in cartilage of mice (C57/BL). J Nutr 1999; 129:1891-1895.

8 Kim SK, Kim YT, Byun HG, Park PJ, Ito H: Purification and characterization of antioxidative peptides from bovine skin. J Biochem Mol Biol 2001;34:219-224.
9 Mendis E, Rajapakse N, Kim SK: Antioxidant properties of a radical-scavenging peptide purified from enzymatically prepared fish skin gelatin hydrolysate. J Agric Food Chem 2005; 53:581-587.

10 Mendis E, Rajapakse N, Byun HG, Kim SK Investigation of jumbo squid (Dosidicus gigas) skin gelatin peptides for their in vitro antioxidant effects. Life Sci 2005;77:21662178.

11 Li B, Chen F, Wang X, Ji B, Wu Y: Isolation and identification of antioxidative peptides from porcine collagen hydrolysate by consecutive chromatography and electrospray ionization mass spectrometry. Food Chem 2007; 102:1135-1143. 
$\checkmark 12$ Postlethwaite AE, Seyer JM, Kang AH: Chemotactic attraction of human fibroblasts to type I, II, and III collagens and collagen-derived peptides. Proc Natl Acad Sci USA 1978; 75:871-875.

-13 Shigemura Y, Iwai K, Morimatsu F, Iwamoto T, Mori T, Oda C, Taira T, Park EY, Nakamura Y, Sato K: Effect of prolyl-hydroxyproline (Pro-Hyp), a food-derived collagen peptide in human blood, on growth of fibroblasts from mouse skin. J Agric Food Chem 2009;57: 444-449.

14 Matsuda N, Koyama Y, Hosaka Y, Ueda H, Watanabe T, Araya T, Irie S, Takehana K: Effects of ingestion of collagen peptide on collagen fibrils and glycosaminoglycans in the dermis. J Nutr Sci Vitaminol (Tokyo) 2006; 52:211-215

15 Tanaka M, Koyama Y-I, Nomura Y: Effects of collagen peptide ingestion on UVB-induced skin damage. Biosci Biotechnol Biochem 2009;73:930-932.

16 Zague V, de F, V, da Costa RM, de Castro GA, Jaeger RG, hado-Santelli GM: Collagen hydrolysate intake increases skin collagen expression and suppresses matrix metalloproteinase 2 activity. J Med Food 2011;14:618624

17 Segger D, Matthies A, Saldeen T: Supplementation with Eskimo Skin Care improves skin elasticity in women. A pilot study. J Dermato$\log$ Treat 2008; 19:279-283.

18 Segger D, Schonlau F: Supplementation with Evelle improves skin smoothness and elasticity in a double-blind, placebo-controlled study with 62 women. J Dermatolog Treat 2004; 15:222-226.

19 Krueger N, Luebberding S, Oltmer M, Streker M, Kerscher M: Age-related changes in skin mechanical properties: a quantitative evaluation of 120 female subjects. Skin Res Technol 2011;17:141-148.

20 Ryu HS, Joo YH, Kim SO, Park KC, Youn SW: Influence of age and regional differences on skin elasticity as measured by the Cutometer. Skin Res Technol 2008;14:354-358.

-21 Batisse D, Bazin R, Baldeweck T, Querleux B, Leveque JL: Influence of age on the wrinkling capacities of skin. Skin Res Technol 2002;8: 148-154.

22 Frei V, Perrier E, Orly I, Huc A, Augustin C, Damour O: Activation of fibroblast metabolism in a dermal and skin equivalent model: a screening test for activity of peptides. Int J Cosmet Sci 1998;20:159-173.

-23 Liang J, Pei X, Zhang Z, Wang N, Wang J, Li $Y$ : The protective effects of long-term oral administration of marine collagen hydrolysate from Chum Salmon on collagen matrix homeostasis in the chronological aged skin of Sprague-Dawley male rats. J Food Sci 2010; 75: $\mathrm{H} 230-\mathrm{H} 238$
24 Paul C, Maumus-Robert S, MazereeuwHautier J, Guyen CN, Saudez X, Schmitt AM: Prevalence and risk factors for xerosis in the elderly: a cross-sectional epidemiological study in primary care. Dermatology 2011;223: 260-265.

25 Nishimori Y, Edwars C, Pearse A, Matsumoto K, Kawai M, Marks R. Degenerative alterations of dermal collagen fiber bundles in photodamaged human skin and UV-irradiated hairless mouse skin: possible effect on decreasing skin mechanical properties and appearance of wrinkles. J Invest Dermatol 2001; 117:1458-1463.

26 Sumino H, Ichikawa S, Abe M, Endo Y, Ishikawa O, Kurabayashi M: Effects of aging, menopause, and hormone replacement therapy on forearm skin elasticity in women. J Am Geriatr Soc 2004;52:945-949.

27 Vuillermoz B, Wegrowski Y, Contet-Audonneau JL, Danoux L, Pauly G, Maquart FX: Influence of aging on glycosaminoglycans and small leucine-rich proteoglycans production by skin fibroblasts. Mol Cell Biochem 2005; 277:63-72.

28 Chung JH, Seo JY, Choi HR, Lee MK, Youn CS, Rhie G, Cho KH, Kim KH, Park KC, Eun HC: Modulation of skin collagen metabolism in aged and photoaged human skin in vivo. J Invest Dermatol 2001;117:1218-1224.

29 Tokudome Y, Nakamura K, Kage M, Todo H, Sugibayashi K, Hashimoto F: Effects of soybean peptide and collagen peptide on collagen synthesis in normal human dermal fibroblasts. Int J Food Sci Nutr 2012;63:689-695.

30 Castro GA, Maria DA, Bouhallab S, Sgarbieri VC: In vitro impact of a whey protein isolate (WPI) and collagen hydrolysates (CHs) on B16F10 melanoma cell proliferation. J Dermatol Sci 2009;56:51-57.

31 Lee J-H, Seo J-H, Park Y-H, Lim K-M, Lee S-J: The effect of hydroxyproline and Pro-Hyp dipeptide on UV-damaged skin of hairless mice. Korean J Food Sci Technol 2008;40: 436-442.

32 Li GY, Fukunaga S, Takenouchi K, Nakamura F: Comparative study of the physiological properties of collagen, gelatin and collagen hydrolysate as cosmetic materials. Int J Cosmet Sci 2005;27:101-106.

33 Pei XR, Yang RY, Zhang ZF, Xu YJ, Han XL, Wang JB, Li Y: Effects of marine collagen peptide on delaying the skin aging. Zhonghua $\mathrm{Yu}$ Fang Yi Xue Za Zhi 2008;42:235-238.

-34 Zhuang Y, Hou H, Zhao X, Zhang Z, Li B: Effects of collagen and collagen hydrolysate from jellyfish (Rhopilema esculentum) on mice skin photoaging induced by UV irradiation. J Food Sci 2009;74:H183-H188.
35 Bauza E, Oberto G, Berghi A, Dal CF, Domloge N: Collagen-like peptide exhibits a remarkable antiwrinkle effect on the skin when topically applied: in vivo study. Int J Tissue React 2004;26:105-111.

36 Haftek M, Mac-Mary S, Le Bitoux MA, Creidi P, Seite S, Rougier A, Humbert P: Clinical, biometric and structural evaluation of the long-term effects of a topical treatment with ascorbic acid and madecassoside in photoaged human skin. Exp Dermatol 2008; 17: 946-952.

37 Loden M: Barrier recovery and influence of irritant stimuli in skin treated with a moisturizing cream. Contact Dermatitis 1997;36: 256-260.

38 Draelos ZD: Active agents in common skin care products. Plast Reconstr Surg 2010;125: 719-724.

-39 Xhauflaire-Uhoda E, Fontaine K, Pierard GE: Kinetics of moisturizing and firming effects of cosmetic formulations. Int J Cosmet Sci 2008; 30:131-138.

40 Buraczewska I, Berne B, Lindberg M, Torma $\mathrm{H}$, Loden $\mathrm{M}$ : Changes in skin barrier function following long-term treatment with moisturizers: a randomized controlled trial. Br J Dermatol 2007;156:492-498.

41 Varani J, Warner RL, Gharaee-Kermani M, Phan SH, Kang S, Chung JH, Wang ZQ, Datta SC, Fisher GJ, Voorhees JJ: Vitamin A antagonizes decreased cell growth and elevated collagen-degrading matrix metalloproteinases and stimulates collagen accumulation in naturally aged human skin. J Invest Dermatol 2000;114:480-486.

42 Fisher GJ, Wang ZQ, Datta SC, Varani J, Kang S, Voorhees JJ: Pathophysiology of premature skin aging induced by ultraviolet light. $\mathrm{N}$ Engl J Med 1997;337:1419-1428.

43 Marini A, Grether-Beck S, Jaenicke T, Weber M, Burki C, Formann P, Brenden H, Schonlau F, Krutmann J: Pycnogenol ${ }^{\circledR}$ effects on skin elasticity and hydration coincide with increased gene expressions of collagen type I and hyaluronic acid synthase in women. Skin Pharmacol Physiol 2012;25:86-92.

44 Siddappa K: Dry skin conditions, eczema and emollients in their management. Indian J Dermatol Venereol Leprol 2003;69:69-75.

45 Baek JH, Lee MY, Koh JS: Relationship between clinical features of facial dry skin and biophysical parameters in Asians. Int J Cosmet Sci 2011;33:222-227.

46 Seyfarth F, Schliemann S, Antonov D, Elsner $P$ : Dry skin, barrier function, and irritant contact dermatitis in the elderly. Clin Dermatol 2011;29:31-36

47 Sato J, Yanai M, Hirao T, Denda M: Water content and thickness of the stratum corneum contribute to skin surface morphology. Arch Dermatol Res 2000;292:412-417.
Beneficial Effects of Specific Collagen

Peptides on Human Skin Physiology
Skin Pharmacol Physiol 2014;27:47-55

DOI: $10.1159 / 000351376$ 